\title{
Entre evidências e negligências: cobertura e invisibilidade de temas de saúde na mídia impressa portuguesa
}

\author{
Between evidence and negligence: coverage and invisibility \\ of health topics in the Portuguese printed media
}

Aline Guio Cavaca ${ }^{1}$

Paulo Roberto Vasconcellos-Silva ${ }^{1}$

Patrícia Ferreira ${ }^{2}$

João Arriscado Nunes ${ }^{2}$

${ }^{1}$ Escola Nacional de Saúde Pública, Fiocruz. R. Leopoldo Bulhões 1480, Manguinhos. 21041-210 Rio de Janeiro RJ Brasil. alineguica@hotmail.com

${ }^{2}$ Centro de Estudos Sociais,

Universidade de Coimbra.
Abstract The scope of this study is to conduct an assessment of the media coverage and dissemination of health issues in Portugal in order to problematize the aspects of coverage and invisibility of health topics and establish the themes neglected in media coverage. To achieve this, the coverage on health issues in the Portuguese daily newspaper Público was compared with the epidemiological context regarding health priorities and the perceptions of key players on media dissemination and the themes that are relevant to the Portuguese population. The results showed that the recurrent health-associated themes do not deal with diseases per se, but with the politics and economics of health and medication. The themes neglected in media coverage identified in the Portuguese context include: communicable diseases, such as hepatitis and tuberculosis; issues related to mental health and suicide; and ailments and social consequences associated with the economic crisis that has beset Portugal recently. From the standpoint of the people interviewed, other neglected diseases include hemochromatosis and other rare diseases. In tandem with this, the study highlights the well covered media themes that revolve around the lives and activities of celebrities, which are exhaustively aired in the communication media in the country.

Key words Communication in health, Public health, Mass media
Resumo Este estudo objetiva realizar uma análise sobre a divulgação midiática da saúde em Portugal, a fim de problematizar as questões da cobertura e invisibilidade dos temas de saúde, as quais apontariam Temas Midiaticamente Negligenciados. Para tanto, foram comparadas a cobertura de saúde do Jornal Público com o contexto epidemiológico sobre as prioridades de saúde e com as percepções dos atores-chave acerca da divulgação midiática e dos temas relevantes à população portuguesa. Evidenciou-se nos resultados que os temas ligados à saúde mais recorrentes na mídia portuguesa não se referem às doenças propriamente ditas, mas às Políticas e à Economia da saúde e medicamentos. Foram identificados como Temas Midiaticamente Negligenciados no contexto lusitano as doenças transmissíveis, como as hepatites e a tuberculose; questões relacionadas à Saúde Mental e ao suicídio; as enfermidades e consequências sociais da crise econômica que assola o país e, a partir da percepção dos comunicadores entrevistados, as Doenças Negligenciadas, a Hemocromatose e demais doenças raras. Paralelo a isso, o estudo destaca como Temas Midiaticamente Evidenciados as mazelas relacionadas às celebridades, conjunturais e exaustivamente exploradas pelos veículos de comunicação.

Palavras-chave Comunicação em saúde, Saúde pública, Meios de comunicação de massa 


\section{Introdução}

Enquanto campo social - microcosmo dotado de leis próprias ${ }^{1}$-, a mídia é uma instituição delimitada pela sua própria esfera de legitimidade na definição, na imposição e na defesa de uma determinada hierarquia de valores ${ }^{2}$. Porém, detém uma legitimidade singular: ao contrário de outros campos que possuem sistemas morais e físicos de sanções aos transgressores de suas ordens e regras, a mídia pode limitar (ou até mesmo privar) a publicidade e visibilidade pública dos que não se sujeitam aos seus valores e normas, de forma a originar uma semi-inexistência social ${ }^{2}$ que preserva e perpetua iniquidades e vitimiza os segmentos mais vulneráveis no contexto de uma sociedade mediatizada.

Assim sendo, entende-se que uma veiculação crítica dos assuntos de saúde promove sua visibilidade pública, que se faz determinante na construção e manutenção do lugar de fala dos indivíduos no espaço público e no mercado simbólico das práticas e políticas de saúde ${ }^{3,4}$, bem como na capacidade de pautar os assuntos evidenciados pela mídia no dia a dia da população, incitando a discussão política sobre estes.

Em Portugal, o campo da comunicação da saúde é ocupado por especialistas e/ou profissionais da Saúde Pública e da Promoção da Saúde. As instituições associadas à investigação e às políticas públicas nestas áreas têm sido incentivadas a promover a sua produção e a contribuir para a melhoria da literacia da saúde da população portuguesa através da criação de gabinetes de comunicação que divulgam informações sobre saúde, realização de atividades lúdico-educativas, entre outras ${ }^{5}$. Paralelamente, a cobertura midiática dos temas de saúde tem se ampliado, indo ao encontro das expectativas das sociedades portuguesa e brasileira, ambas altamente medicalizadas ${ }^{6}$. O jornalismo de saúde tem lutado para conquistar um lugar nos órgãos de comunicação social e também nas instituições ligadas à saúde, ainda que haja desafios associados à cobertura de notícias deste tema, tais como a definição das agendas dos órgãos de comunicação social e a formação específica dos jornalistas para cobrir notícias desta pauta ${ }^{5}$.

Nesse contexto, questões relacionadas à saúde são pautas frequentes e sumamente valorizadas nos jornais diários. Contudo, os espaços ocupados pela temática em destaque são orientados por uma agenda (seja jornalística ou dos comunicadores institucionais) cujos atributos valorativos, cogita-se, não contemplam os inte- resses e as necessidades sociais da questão. Pelo contrário, a agenda da comunicação midiática da saúde parece definir-se, principalmente, a partir da divulgação do desenvolvimento da investigação biomédica e farmacêutica e aspectos ligados à governação da saúde ao nível nacional.

Decerto, tais interesses são, muitas vezes, legitimados pela saúde pública e atores circundantes, uma vez que o Sistema Nacional de Saúde português (SNS) tem estado tencionado, desde o seu surgimento, em 1979, por interesses contraditórios e instáveis, entre um polo mercantilista - no qual a saúde é entendida como mercadoria e sujeita às regras de mercado- e outro centrado no bem comum, no interesse público e que considera as doenças como questões socialmente determinadas ${ }^{7}$.

Nesse sentido, as Doenças Midiaticamente Negligenciadas ${ }^{8}$ se definiriam como sentidos e temáticas de subexposição, apesar de sua potencial relevância nos rumos de uma sociedade que carece de informações para as decisões políticas mais substantivas.

Essa discussão, no contexto brasileiro e dos demais países que sofrem com doenças endêmicas, tem como base o entendimento de "negligência" inspirado pelo conceito de "Doenças Negligenciadas” (DN). Proposto pela Organização Mundial de Saúde (OMS)/ Médicos Sem Fronteiras $(\mathrm{MSF})^{9}$, as DN colocam em pauta a questão da negligência pública (política, econômica e social) ligada a tais mazelas, tradicionalmente associadas à situação de pobreza, às iniquidades em saúde $\mathrm{e}$ aos "países em vias de desenvolvimento". Entende-se, assim, que a condição de visibilidade pública dessas doenças, bem como de outros problemas de saúde relacionados às iniquidades sociais, poderia proporcionar a inclusão dessas questões no debate de prioridades políticas e em pesquisas, norteando as agendas governamentais ${ }^{3,8}$.

No cenário lusitano, esta pesquisa foi discutida inicialmente no seio de projetos de investigação coordenados pelo Centro de Estudos Sociais da Universidade de Coimbra (CES), que se dedicavam às relações entre a Ciência e a Sociedade ${ }^{10}$. Procurou-se analisar a pertinência e o enquadramento desta categoria no contexto da comunicação e saúde em Portugal, sabendo antecipadamente que se centra em uma cobertura mais conjuntural das políticas públicas de saúde ${ }^{11,12} \mathrm{e}$ não priorizando a divulgação midiática de doenças. O sentido de negligência aplica-se, neste contexto, ao descuro de temas de saúde importantes, não restrito ao escopo das doenças, embora centrais a determinados públicos e à Saúde Coletiva. 
Desta maneira, este estudo objetiva realizar uma análise sobre a divulgação midiática da saúde em Portugal, a fim de problematizar as questões da cobertura e invisibilidade dos temas de saúde, de maneira a apontar os Temas Midiaticamente Negligenciados.

\section{Metodologia}

O presente estudo de caso analisou a cobertura de saúde do Jornal Público, no período de 01 de maio de 2013 a 31 de julho de 2013, relacionando-a ao contexto epidemiológico de saúde em Portugal - identificado a partir de documentos oficiais - e à compreensão de atores-chave a respeito da divulgação midiática da saúde no país. O período de estudo e a amostra foram selecionados pelos pesquisadores a partir do início da parceria interinstitucional (estágio doutoral de uma das pesquisadoras) e do acesso ao acervo do periódico selecionado, respeitando os critérios de representatividade e repetição temática. Além disso, foi considerado o período de lançamento e abrangência dos documentos selecionados para análise ${ }^{13,14}$, bem como a identificação de sujeitos que tiveram relevância na divulgação midiática de temas de saúde no período.

Segundo Tobar e Yalour ${ }^{15}$, o estudo de caso representa um tipo de pesquisa circunscrito a poucas unidades de análise, cuja riqueza não se encontra em sua extensão, mas no aprofundamento analítico e nas inferências derivadas de suas questões. Face ao exposto, a proposta metodológica assume a relevância de se considerar diferentes perspectivas das prioridades de saúde da população (epidemiológicas e percepções dos sujeitos), valendo-se dessa multiplicidade de aportes empíricos e interpretativos que se tornam complementares e enriquecedores no contexto do estudo.

Dessa maneira, lançamos mão da triangulação de métodos para análise do objeto, uma vez que pesquisas em áreas de interface suscitam abordagens que permitem o diálogo entre áreas distintas e interdisciplinares, além de estratégias de investigação que combinem métodos e técnicas, ao analisar a realidade por diversos ângulos ${ }^{16}$. $\mathrm{O}$ uso da triangulação promoveu a combinação de múltiplas estratégias metodológicas, capazes de apreender as dimensões qualitativas - inspiradas na tradição interpretativa das ciências sociais, com o objetivo de compreender o problema de pesquisa a partir dos pontos de vista dos participantes - e quantitativas do objeto, no que diz respeito às análises do contexto de saúde via indicadores epidemiológicos e das frequências das temáticas dos jornais.

\section{Análise Midiática}

O jornal Público foi fundado em 1990 e representa um dos cinco jornais portugueses mais importantes, sendo uma mídia de referência no campo da imprensa escrita, com uma tiragem de 45.041 exemplares no terceiro bimestre de $2013^{17}$.

Procedimentos: Entre maio e julho de 2013, foram compiladas todas as matérias referentes às questões de saúde, quando pauta principal ou derivada. Não foram incluídas as matérias sobre doenças e agravos em contexto considerado irrelevante para este estudo (propagandas, promoção de eventos privados, palavras sinônimas, referências a concursos, etc.). O material foi coletado em formato impresso e digital (PDFs acessados no site do jornal) e as notícias impressas foram catalogadas em um banco de dados. Os arquivos em PDF foram organizados no software MAXQDA (versão 11.0.8), para facilitar a conexão dos textos e demais informações relevantes à pesquisa (notas, transcrições, referências bibliográficas, diário de campo), como uma "base de dados interna" ${ }^{18}$. Todo o material foi classificado segundo seus temas e período de publicação. Para calcular frequências absolutas e relativas das temáticas, foi usado o pacote estatístico SPSS 16.0. Os temas foram hierarquizados em ordem decrescente, de acordo com a frequência de veiculação no jornal, no período de estudo.

\section{Análise do contexto epidemiológico das prioridades em saúde}

Para caracterizar o contexto epidemiológico do país no período, foram considerados os dados oficiais divulgados no "Plano Nacional de Saúde (PNS) 2012-2016"13 e no "Relatório de Primavera 2013"14, organizado pelo Observatório Português dos Sistemas de Saúde. O PNS propõe caracterizar o estado de saúde da população, contribuindo para a identificação de avanços potenciais nesse campo ${ }^{13}$.

Já o Relatório de Primavera apresenta uma análise, de forma independente e frequentemente crítica, da evolução do sistema de saúde português e os fatores que a determinam. Para tanto, utiliza como base não somente os indicadores usuais, mas também estudos internacionais, trabalhos de investigação e resultados de inquéritos da Escola Nacional de Saúde Pública, compondo, 
assim, uma leitura crítica da situação de saúde do país ${ }^{14}$.

Procedimentos: Os documentos foram analisados na íntegra pelos pesquisadores e foram extraídas as principais informações concernentes ao contexto epidemiológico de Portugal no período de estudo, tais como: principais causas de mortalidade e morbidade, acesso aos serviços de saúde, cobertura de vacinação, bem como características do contexto de crise econômica e suas influências na saúde.

\section{Entrevistas com atores-chave: perspectivas} da divulgação midiática da saúde

Foram conduzidas entrevistas em profundidade com três sujeitos relacionados à divulgação midiática da saúde em Portugal em diferentes perspectivas, consideradas representativas e complementares no que diz respeito aos interesses da saúde: um representante da Associação Portuguesa de Hemocromatose (Associação de pacientes), um profissional do Instituto de $\mathrm{Hi}$ giene e Medicina Tropical (IHMT) (Comunicação e Saúde) e um jornalista que cobre a pauta de saúde em um importante jornal português (Mídia). Dessa maneira, os principais temas de saúde veiculados foram identificados, bem como as temáticas descontempladas sob a perspectiva desses atores.

Procedimentos: As entrevistas semiestruturadas foram orientadas por um roteiro com seis perguntas relacionadas à divulgação midiática e sua relação com o contexto luso de saúde. As entrevistas foram transcritas com uso do Software F4 e analisadas através do MAXQDA (versão 11.0.8). Foi empregada a Análise Temática de Conteúdo, técnica que visa identificar os núcleos de sentido que compõem a comunicação e cuja presença e frequência podem sugerir alguma relevância transcendente para o objeto analítico em questão ${ }^{19}$, neste caso, no que diz respeito às evidências e negligências midiáticas.

A pesquisa foi aprovada no Comitê de Ética e Pesquisa da Escola Nacional de Saúde Pública Sérgio Arouca e todos os participantes assinaram o Termo de Consentimento Livre e Esclarecido.

\section{Resultados e discussão}

Através da análise comparativa do material empírico (matérias de jornais, dados epidemiológicos e entrevistas), foram identificados os temas de saúde mais recorrentes, bem como os que, apesar de sua alta relevância, apresentaram baixa cobertura - os Temas Midiaticamente Negligenciados no contexto de saúde português.

Relativamente ao ponto um, foram identificadas 154 matérias relacionadas à saúde no jornal Público, no período de estudo. Apenas 21,2\% das matérias apresentaram destaque na primeira página. Porém, a maioria destas apresentava-se em páginas inteiras $(36,5 \%)$, o que parece denotar abordagens relevantes e aprofundadas. As temáticas de saúde mais frequentes nos meses de estudo são representadas na Tabela 1 .

\section{Contexto epidemiológico das prioridades em saúde - PNS e Relatório de Primavera}

A análise desses documentos permitiu conhecer melhor os contextos de saúde e socioeconômico de Portugal, muito importantes no entendimento das necessidades sociais, as quais conformam o "interesse público" de uma maneira geral e que deveriam ser levadas em consideração nos critérios de noticiabilidade midiáticos, além dos tradicionais "valores-notícia"20.

Atualmente, segundo o PNS, a população continental de Portugal é de 10.047.083 habitantes, contudo, verifica-se um decréscimo do índi-

Tabela 1. Temáticas de saúde veiculadas no Jornal Público no período de 01 de maio de 2013 a 31 de julho de 2013.

\begin{tabular}{lrr}
\hline & N & (\%) \\
\hline $\begin{array}{l}\text { Temáticas específicas } \\
\quad \text { Medicamentos e Indústria }\end{array}$ & 18 & $11,7 \%$ \\
$\quad \begin{array}{lr}\text { Farmacêutica } \\
\text { Administração do Sistema Nacional }\end{array}$ & 15 & $9,7 \%$ \\
$\quad$ de Saúde & & \\
$\quad$ Questões trabalhistas dos & 13 & $8,4 \%$ \\
profissionais de saúde & & \\
Câncer (Cancro) & 12 & $7,8 \%$ \\
$\quad$ Denúncias em saúde & 8 & $5,2 \%$ \\
$\quad$ Biologia, Biotecnologia e & 8 & $5,2 \%$ \\
$\quad$ Neurociências & & \\
$\quad$ Alimentação & 7 & $4,5 \%$ \\
$\quad$ HIV/Aids & 7 & $4,5 \%$ \\
$\quad$ Consumo/dependência de tabaco, & 6 & $3,9 \%$ \\
jogos, álcool e outras drogas & & \\
$\quad$ Saúde materno-infantil & 6 & $3,9 \%$ \\
$\quad$ Mercado/economia da saúde & 5 & $3,2 \%$ \\
$\quad$ Saúde Mental & 5 & $3,2 \%$ \\
Outras Temáticas & 44 & $28,6 \%$ \\
Total & 154 & \\
\end{tabular}


ce sintético de fecundidade, o que não permite a renovação de gerações ${ }^{13}$, com consequências diretas nas demandas dos serviços de saúde. O documento assinala o aumento da mortalidade prematura por doenças atribuíveis ao álcool e por suicídio, que podem estar relacionadas ao contexto perverso de crise econômica no país. Sobre o acesso a serviços de saúde, cita dados do Censo de 2006 que afirma que $81,1 \%$ da população utilizava o Sistema Nacional de Saúde. Apenas $10,5 \%$ da população continental declarou possuir Seguro de Saúde. Já o Programa Nacional de Vacinação, de caráter universal e gratuito, ultrapassa a cobertura de $95 \%$ da população, sendo o programa governamental com melhor custo-efetividade do país.

A mortalidade e morbidade por doenças infecciosas tem tido um decréscimo significativo, a partir da implementação do Programa Nacional de Vacinação. Porém, a incidência de Tuberculose (23,4 por 100000 habitantes) e infecção por HIV (9/100 000 habitantes) em Portugal é ainda muito elevada se comparada com a média dos cinco países da União Europeia com melhores desempenhos nesse campo. Destaca como principais causas de mortalidade, para ambos os sexos: doenças circulatórias (32\%); tumores malignos (23\%) e doenças respiratórias (11,1\%). Entre os homens, destacam-se os acidentes, envenenamentos e violência; e, entre as mulheres, diabetes mellitus. Outro dado relevante informado é que os problemas de saúde mental representam doenças com mortalidade baixa e taxas de incidência elevadas, o que suscita atenção na definição política de áreas prioritárias.

A síntese apresentada pelo Relatório de Primavera 2013 alinha-se a tais resultados, reiterando que, para analisar a saúde em Portugal, devese, necessariamente, considerar o contexto de crise econômica em que o país e a Europa encontram-se mergulhados. Por um lado, percebem-se indicadores que demonstram resiliência de alguns setores, como, por exemplo, as demonstrações de criatividade e solidariedade para além da ação do Estado e, por outro, vários outros setores apresentam sinais de exaustão, resignação e desmotivação, com claras repercussões na disponibilidade de cuidados ${ }^{14}$.

Tal documento apresenta algumas características deste contexto de crise no país: taxa de desemprego maior entre os mais jovens $(16,9 \%)$; recessão de 3,2\% do PIB; famílias que não conseguem pagar o empréstimo da casa, devolvem-na ao banco e regressam a casa dos pais; aumento do número de crianças com carência alimentar.
Denuncia, ainda, que foram feitos mais cortes que o previsto no repasse para o financiamento do Sistema Nacional de Saúde (SNS). O OPSS questiona, portanto, as razões dos cortes, que ultrapassam os valores negociados para o resgate financeiro do país com a entidade conhecida como Troika - Banco Central Europeu, Fundo Monetário Internacional e União Europeia -, neste setor que funciona como uma espécie de estabilizador social automático.

\section{Entrevistas com informantes-chave}

Após a pré-análise e leitura flutuante de todo o material empírico, foram realizadas a codificação e categorização das entrevistas, dando origem a cinco categorias analíticas, representadas abaixo (Quadro 1).

\section{Temas recorrentes, invisibilidade}

\section{das doenças, necessidade $\mathrm{x}$ recorrência}

Em relação às doenças mais recorrentes na mídia, foram destacadas pelos entrevistados as de alta prevalência, alta morbidade e mortalidade na população portuguesa, as quais contam com associações de doentes ativas, como a diabetes, hipertensão arterial, câncer e doenças cardíacas. A Aids ainda possui alguma relevância midiática e as infecções respiratórias começam a aparecer.

Ao fazer uma triangulação dos resultados do estudo, percebe-se que as principais temáticas abordadas na mídia lusa - analisadas tanto pelo levantamento documental quanto a partir da percepção dos sujeitos entrevistados - coincidiram consideravelmente com as principais causas de mortalidade prematura (AVPP) (Quadro 2).

Pode-se, assim, observar que, quanto maior a patologização da doença, maior a midiatização da mesma. Entretanto, sabe-se que a relevância epidemiológica nem sempre é determinante nesse processo, uma vez que a midiatização também é altamente influenciada pelo grau de politização

Quadro 1. Categorias analíticas baseadas na Análise de Conteúdo das entrevistas, Portugal -2013.

Temas recorrentes
Invisibilidade das doenças
Necessidade X Recorrência
Negligência Midiática: temas relevantes invisíveis
Temas Midiaticamente Evidenciados




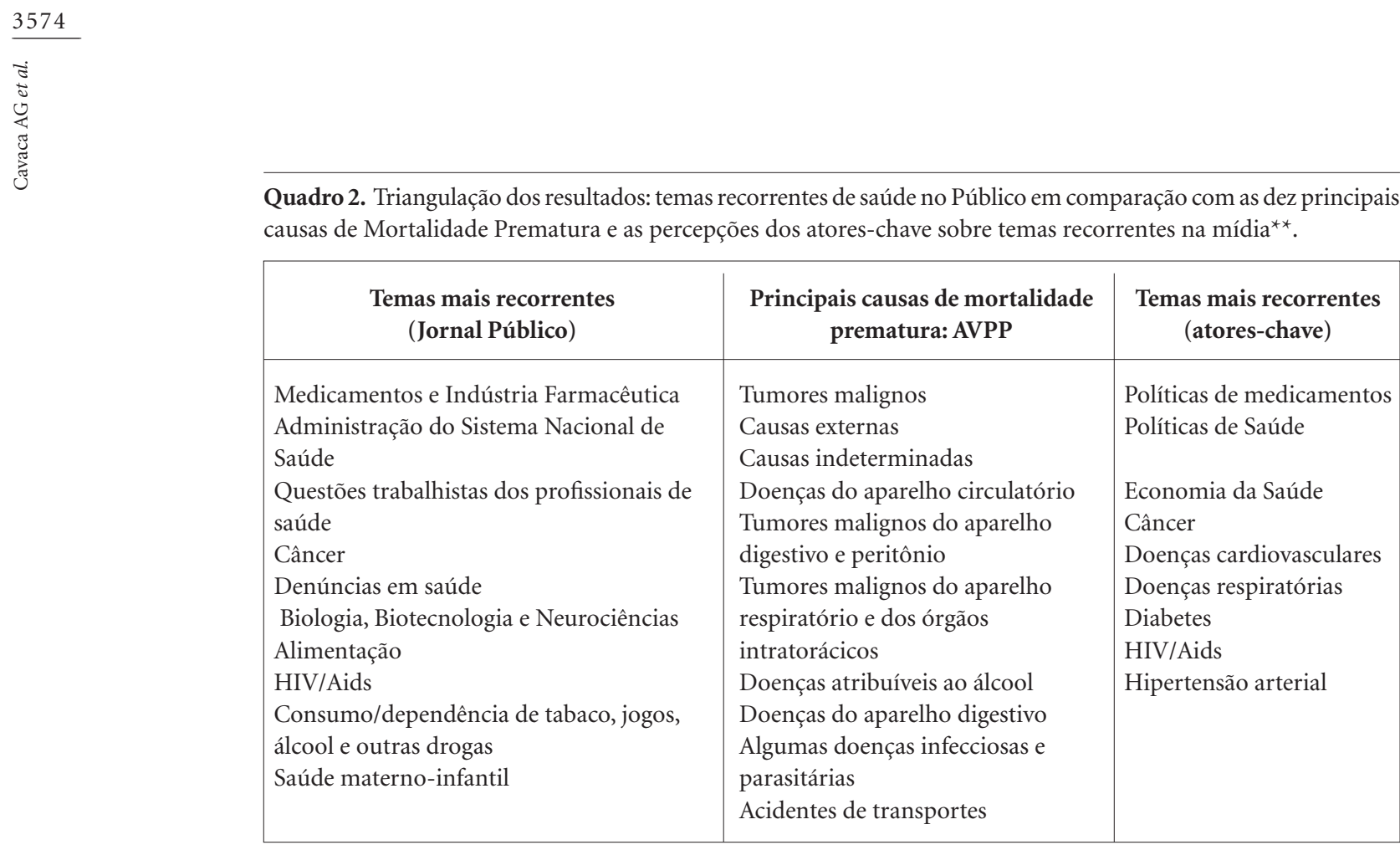

“AVPP: O indicador Anos de Vida Potenciais Perdidos quantifica o número de anos de vida não vividos quando a morte ocorre em determinada idade abaixo da qual se considera a morte prematura. ${ }^{* *}$ Temas recorrentes de saúde veiculados no jornal Público em comparação com as dez principais causas de Mortalidade Prematura: medidas pelos Anos de Vida Potenciais Perdidos (AVPP/100000 habitantes) em Portugal Continental, 2010 e os temas de saúde recorrentes na mídia de acordo com a percepção dos atores-chave entrevistados.

e institucionalização da questão de saúde e pelos atores porta-vozes da questão. Tais "lançadores de alerta" ${ }^{21}$ ou "News promoters" tornam-se nucleares nesse processo, por representarem fontes ativas ou grupos de interesses mobilizados para influenciar a pauta jornalística, os quais fazem surgir no espaço público determinados assuntos, por exemplo, no caso o protagonismo de associações de pacientes, celebridades ou autoridades, ou lançamento de políticas públicas.

Porém, de acordo com a percepção da jornalista entrevistada, os temas de saúde mais recorrentes na mídia portuguesa não dizem respeito às doenças propriamente ditas, mas, sim, às políticas de saúde, à economia da saúde e às políticas de medicamentos. Inclusive, questiona se seria função de um jornal diário falar sobre doenças, como se percebe no trecho abaixo:

$X$ : Por que...pra já somos poucos... a fazer saúde e... eu acho que é [...] absolutamente impossível cobrir toda a gama de doenças...quer dizer, escolher uma em detrimento de outra...nós somos inundados com e-mails de agências que propõem extratos de uma doença. Se calhar, eu acho que não cabe muito a um jornal diário estar a fazer um trabalho de falar de doenças só por falar, a não ser que a doença seja notícia, por alguma circunstância específica.
A informação prestada pela jornalista confirma-se na prevalência desses temas na análise midiática (Tabela 1). Sendo assim, observa-se, em Portugal, a priorização de coberturas conjunturais e de políticas públicas do país em contraposição à divulgação e discussão das doenças ${ }^{12,22}$. Quando abordadas, as doenças mais mediatizadas nos anos de 2010 a 2013, segundo Lopes et al. ${ }^{11}$, foram os tumores, doenças mentais, transplantes, AIDS e gripe.

No país, de acordo com os entrevistados, as doenças infecciosas, as doenças raras ou as doenças negligenciadas (DN) só aparecem quando agregam elementos de noticiabilidade usuais à Indústria Jornalística, como quando surgem surtos, epidemias, alguma inovação da indústria farmacêutica ou adoecimento de celebridades. Percebe-se que a gripe A (H1N1) obteve uma hipermediatização devido à pandemia do ano de $2009^{11}$, enquanto a dengue recebeu uma cobertura noticiosa com conotação alarmante em 2012, em razão dos casos notificados da doença no território português da Ilha da Madeira ${ }^{23}$.

O profissional do IHMT reafirma essa observação, ao comparar o atual papel que desempenha na divulgação das DNs com a função que exercia no Ministério da Saúde, junto à equipe de elaboração do Plano Nacional de Saúde: 
Y: [...] No MS eu estava no Alto Comissariado da Saúde, que era o organismo responsável pelo PNS, e esse plano privilegiava determinadas doenças que eram consideradas prioritárias [...] como o cancro, as Doenças Cardiovasculares, SIDA e a Patologia na área da saúde mental [...] Então é o oposto do que estamos a falar aqui...são as doenças que têm mais visibilidade midiática, são as doenças mais fáceis de comunicar, são aquelas que basicamente eu não precisava ter sequer uma atitude muito pró-ativa com os jornalistas, por que os jornalistas telefonavam para perguntar qual era o panorama nacional dessas doenças.

Dessa maneira, percebe-se que a divulgação de doenças pela mídia portuguesa tangencia o entendimento de necessidades de saúde da população $=$ patologias de alta prevalência $=$ recorrência na mídia, teoricamente, o que seria de interesse público.

Em linhas gerais, de acordo com Silva ${ }^{12}$, privilegiam-se os mesmos "valores-notícia” referentes aos outros temas da agenda noticiosa, a saber: a negatividade, a controvérsia, o conflito, a proximidade, a novidade e a dramatização, a par da relevância atribuída especificamente a alguns atores com significativa capacidade de agendamento pelo estatuto social e político que os detêm.

Porém, o "interesse público" pode ser visto como uma categoria socialmente determinada ou prescrita? No caso do "problema público", no sentido de interesse geral, considera-se o que se avalia essencial para uma sociedade ${ }^{21}$. Essa avaliação, no entanto, é feita a partir de determinado prisma, um lugar de interlocução no Mercado Simbólico ${ }^{4,24}$ da comunicação, que não necessariamente corresponde à realidade da sociedade como um todo. Considerar o contexto em que os sujeitos estão inseridos para se caracterizar os sentidos de necessidades faz-se essencial na determinação do "interesse público", no que diz respeito à Comunicação e Saúde.

\section{A realidade que não cabe no jornal}

Contudo, existe uma "realidade que não cabe no jornal”, conforme defende Guimarães ${ }^{25}$. Há, segundo a autora, uma "verdadeira arquitetura de valores e hierarquias que são ideologicamente naturalizados e travestidos de interesse público", e, nesse sentido, a mídia é muito bem-sucedida em turvar o que seria de interesse público, de acordo com o que supõe (ou prescreve?) como interesse de alguns públicos.

Entende-se a produção noticiosa através do prisma da teoria do Newsmaking, que articula o entendimento da cultura profissional dos jorna- listas e da organização do trabalho e dos processos produtivos ${ }^{20}$. Porém, não se pode descurar de que há uma série de interesses políticos, econômicos e sociais que, balizados pelo conjunto de critérios de noticiabilidade, acatam a lógica jornalística implicada no Mercado da Atenção, frequentemente desarticulada das necessidades de saúde das populações mais vulneráveis ${ }^{8}$.

Então, faz-se extremamente importante questionar: há problemas invisíveis? Há temas relevantes, porém midiaticamente negligenciados?

De acordo com as entrevistas, doenças transmissíveis são exemplos de temas negligenciados pela mídia. A Saúde Mental também foi qualificada como "esquecida", apesar de representar expressiva morbidade. Registra-se, nesse campo, mortalidade baixa, embora seja alta a prevalência dessas condições ${ }^{13}$ e o suicídio tenha sido percebido como condição subnoticiada. No caso da Tuberculose, ressalta-se o aumento da incidência devido à coinfecção com o HIV, mas não se observa visibilidade midiática à altura do problema, por conta da insuficiente priorização política e de grandes inovações da indústria farmacêutica, que despertem interesse na sua divulgação, o que também já foi suficientemente descrito por outros autores ${ }^{26,27}$.

Além disso, o estigma associado a tais doenças inibem o protagonismo de alguns sujeitos em prol de suas causas, evitando a exposição nos meios de comunicação, como se vê a seguir:

$Z$ : Eu penso que deveria ser dado muito maior ênfase às doenças transmissiveis, por exemplo, o problema da hepatite B, do HIV, da Tuberculose, que acaba por se instalar com mais facilidade agora, em virtude dessas doenças, mas acabam por ser estigmatizantes e que não se fala muito e, portanto, não há muita gente que assuma as bandeiras dessas doenças para tratar delas.

Acredita-se, então, que, assim como a visibilidade pode colaborar para o reconhecimento de necessidades de saúde, a invisibilidade pode levar à negligência ${ }^{3}$. Para além da tradicional - e talvez hipervalorizada - função de disseminação de informações relevantes em saúde, a comunicação também é reconhecida como uma estratégiachave para manter questões relevantes de saúde na agenda pública ${ }^{28}$.

Nesse sentido, acredita-se haver uma relação cíclica entre a cobertura e o enquadramento dos assuntos de saúde na mídia e a proeminência ou obscurantismo desses assuntos no cenário mundial: o ativismo e "advocacy" injetados em diferentes níveis deste ciclo podem influenciar tanto o investimento em novas iniciativas quanto 
a cobertura midiática a respeito dessas questões de saúde ${ }^{29}$.

Porém, cabe também observar que os temas considerados negligenciados nem sempre coincidem com indicadores de prevalência, mortalidade ou prioridades políticas em saúde, justamente por não afetar grandes quantitativos da população local. As DNs, por exemplo, são prevalentes em condições de pobreza, afetam indivíduos de países em desenvolvimento, tropicais, ou até mesmo os imigrantes em Portugal ${ }^{30}$, mas não provocam interesse midiático por não ter perfil de "preocupação nacional”. Sendo assim, a divulgação das DNs também representa um desafio para os comunicadores no país, como se vê a seguir:

Y: Então é um trabalho muito mais difícil, muito mais ingrato... que é tentar que os jornalistas se interessem por um conjunto de doenças que, a partida, eles não têm muita razão para se interessar, por que eles escrevem coisas que afetam diretamente a população portuguesa.

As doenças raras, de maneira semelhante, não despertam grandes interesses midiáticos, mas para as associações de pacientes e para os indivíduos acometidos, a visibilização de suas pautas torna-se essencial para maior conhecimento e interesse da sociedade e por parte do Governo. A Hemocromatose é uma doença rara (5 a 10 por cada mil pessoas podem ser portadoras do gene da doença ${ }^{31}$ ) provocada por distúrbios do metabolismo do ferro, que se acumula principalmente no fígado, coração, pâncreas, pele e articulações, podendo ocasionar insuficiência funcional ${ }^{32}$. Tal patologia agrega não só a negligência midiática, como também outros espectros de negligência política, econômica e até mesmo médica, que, ao ignorar seu diagnóstico diferencial, a torna uma enfermidade subdiagnosticada, subtratada na sociedade.

Entretanto, o protagonismo de um ex-atleta olímpico portador da doença foi extremamente relevante para a divulgação da doença nos media, conforme observa o entrevistado:

$Z$ : É completamente negligenciada, nós temos exemplos e somos vítimas dessa negligenciação porque temos muita dificuldade nos acessos aos programas, por exemplo aqueles que são ouvidos e vistos por muita gente [...] O Antônio Leitão era nossa bandeira em termos de divulgação [...] Depois dele... ele morreu há dois anos e, portanto, não é fácil ter essa bandeira outra vez.

Reitera-se, assim, o poder simbólico da mídia de "fazer crer e fazer ver" ${ }^{4,33}$, o qual possibilitaria protagonismos e visibilização de pautas de saúde não hegemônicas, porém essenciais para deter- minadas populações. Os "lançadores de alerta" exercem tal protagonismo, como por exemplo, o programa Telethon, na França, que uma vez por ano gera visibilidade para doenças raras e, a partir do ativismo voltado para os pacientes portadores e suas dificuldades diárias, põe em evidência as vozes dos doentes e pauta seus problemas no debate público ${ }^{34}$.

Outra questão relevante são as enfermidades e consequências sociais provocadas pelo empobrecimento e precarizações de vínculos sociais e de trabalho advindos da crise econômica que afeta o país. Tal discussão, muitas vezes, é apagada das pautas de governo e da mídia, representando claramente uma questão midiaticamente negligenciada.

Segundo OPSS ${ }^{14}$, tal contexto de crise gera uma diminuição no acesso aos cuidados e de gastos com medicamentos, devido ao empobrecimento dos portugueses, ao aumento das taxas moderadoras, às dificuldades com transportes e à evolução dos tempos de espera. Tais questões não deveriam ser descuradas pela mídia na discussão pública da saúde, pois, assim como a visibilidade exalta problemas de saúde, a invisibilidade pode levar à negligência dos mesmos, ao enfraquecer o apelo político e os protagonismos que ela conduz ${ }^{3}$.

Certas características do campo jornalístico fomentam esse descuro, como sua tendência a privilegiar o aspecto mais visível do mundo social em detrimento das estruturas e dos mecanismos invisíveis que orientam suas ações e pensamentos. As expectativas do público, a obsessão pelo furo jornalístico e a tendência a privilegiar sem discussão a informação mais recente e de acesso mais fácil são invocadas para justificar essa política de simplificação demagógica, frequentemente a mais cínica ${ }^{1}$.

Nesse contexto, a ausência de interesses pelas mudanças sociais mais complexas redobra os efeitos da amnésia estrutural favorecida pela lógica do pensamento do dia a dia, que produz uma representação instanteísta e descontinuísta do mundo. Desarticulada do sistema de relações em que está inserida, a representação (ou sua ausência) midiática de temas relevantes - como a saúde - torna-se des-historicizada e des-historicizante, produzindo uma representação fatalista e favorável à manutenção da ordem estabelecida ${ }^{1}$.

\section{Temas midiaticamente evidenciados}

Contudo, é importante considerar que, da mesma maneira que existem temas relevantes invisibilizados midiaticamente, há questões de saúde com extrema veiculação sem correspondente 
relevância social - temas midiaticamente evidenciados. Questões muitas vezes banais, porém, infladas pelos media em razão de suas características excêntricas, inéditas ou com destaque no mundo artístico, por exemplo. Outras vezes até são patologias graves, que só recebem atenção graças ao acesso dos personagens à mídia. Dessa maneira, expressa-se, assim como defende Tur$\mathrm{cke}^{35}$, a inversão da lógica que baliza a noticiabilidade - de "ser comunicado, porque importante" - para "Importante, porque comunicado".

Tal perversão da lógica da notícia vigora no contexto da sociedade excitada ${ }^{35}$, na qual tudo o que não está em condições de causar uma sensação tende a submergir sob um fluxo caudaloso de informações. Não se deve esquecer, porém, que nenhum sistema de notícias moderno existiria sem tal "perversão" ${ }^{35}$, uma vez que rotular como importante aquilo que divulga compõe a lógica do Mercado da Atenção. Entretanto, acreditamos que a hipervalorização da divulgação de temáticas irrelevantes (ou até mesmo fúteis) em saúde acentua, em sentido contrário, o silenciamento midiático acerca de preocupações relevantes (mesmo que desinteressantes aos media). Tais temáticas alimentam a procrastinação dos problemas, o enfraquecimento das pautas dos movimentos sociais, bem como a alienação dos cidadãos sobre seus direitos constitucionalmente garantidos. Assim, a inquietude em relação a tal negligenciamento relaciona-se, sobretudo, na iniquidade de não tornar visível, quando trata-se de uma função acessível e relevante ${ }^{8}$.

É interessante notar que a imprensa considerada de referência em Portugal não vincula com frequência matérias sobre beleza e estética às matérias sobre saúde, conforme observado no levantamento das notícias e também ressaltado pelos entrevistados (“Apenas na imprensa cor-de -rosa", adverte uma entrevistada). Na contramão dessa tendência, a exacerbada valorização estética, que captura frequente evidência midiática nos mais diversos veículos, parece uma peculiar valorização simbólica no Brasil talvez apensa a questões de mercado ${ }^{36-39}$.

Vale ressaltar que um dos papéis da midiatização é despertar a atenção dos poderes públicos. Quando as pautas são colocadas nos espaços públicos e atingem certo nível de cobertura midiática, elas começam a atrair a atenção. A judicialização e o trabalho das associações de pacientes podem representar alavancas importantes nesse processo, bem como os "lançadores de alertas" ${ }^{40}$.

\section{Considerações finais}

A partir dos resultados apresentados é possível afirmar que os temas ligados à saúde mais recorrentes na mídia impressa portuguesa não se referem às doenças propriamente ditas, mas às políticas e à economia da saúde e medicamentos. Ao contrário do que é usual no Brasil, os produtores de material noticioso questionam a implicação do ethos jornalístico na divulgação de doenças. O campo jornalístico impresso português se define melhor na cobertura conjuntural de políticas públicas ligadas à discussão das condições econômico-políticas de resolutividade das doenças. No caso das Doenças Negligenciadas (DN), o tema apenas se revela ao agregar típicos elementos de noticiabilidade da Indústria Jornalística (surtos, epidemias, alguma inovação da Indústria farmacêutica ou adoecimento de celebridades), enquanto patologias transmissíveis, como as hepatites e a tuberculose, ou até mesmo a saúde mental e suicídio não possuem expressão midiática e protagonismo social, contando com raros "lançadores de alertas", por serem estigmatizantes e, cogita-se, política e midiaticamente "desinteressantes" quando não alinhados a interesses mercadológicos.

É importante perceber, sobretudo ao se traçar um paralelo com a conjuntura nacional, que a divulgação de saúde/doenças se relaciona com a percepção de necessidades de saúde da população. No entanto, sabe-se da "realidade que não cabe no jornal”, ligada à arquitetura de valores e hierarquias ideologicamente naturalizadas e travestidas de interesse público. Dessa maneira, revelaram-se como Temas Midiaticamente Negligenciados no contexto lusitano as doenças transmissíveis, como as hepatites e a tuberculose, questões relacionadas à saúde mental e ao suicídio, as enfermidades e consequências sociais da crise econômica que assola o país e, a partir da percepção dos comunicadores entrevistados, as Doenças Negligenciadas, a hemocromatose e demais doenças raras.

Em Portugal, a veiculação midiática dos temas da saúde e da doença torna-se cada vez mais inextricáveis do engajamento com a biomedicina, as suas formas de conhecimentos hegemônicos, práticas, instituições e profissionais. Paralelo a isso, o estudo destaca como Temas Midiaticamente Evidenciados as mazelas relacionadas às celebridades, exaustiva e desnecessariamente exploradas pelos veículos de comunicação. Já as questões estéticas, ao contrário do Brasil, não recebem muita atenção dos periódicos lusos. 
É certo que a escolha metodológica configura uma dentre diversas outras possibilidades de se analisar a negligência midiática. Pequenas mudanças de foco exporiam diversas outras demandas que "entrariam em cena". Como possibilidade de futuros desdobramentos da pesquisa, almeja-se uma compreensão mais ampliada do processo de invisibilização e produção das ausências na cobertura midiática da saúde.

\section{Colaboradores}

AG Cavaca trabalhou em todas as etapas da pesquisa e redação do artigo; PR Vasconcellos-Silva trabalhou na redação e revisão crítica do artigo; P Ferreira e JA Nunes trabalharam na revisão crítica do artigo e aprovação da versão a ser publicada.

\section{Agradecimentos}

À Capes, pela concessão de bolsa de estudos, no âmbito do Programa Institucional de Bolsas de Doutorado Sanduíche no Exterior - PDSE e ao Programa de Apoio à Pós-graduação - PROAP, do Programa de Pós Graduação em Saúde Pública da ENSP-Fiocruz. 


\section{Referências}

1. Bourdieu P. Sobre a televisão. Rio de Janeiro: Jorge Zahar; 1997.

2. Rodrigues AD. O campo dos media: discursividade, narratividade, máquinas. Lisboa: Vega; 1988.

3. Araújo IS, Moreira AL, Aguiar R. Doenças negligenciadas, comunicação negligenciada. Apontamentos para uma pauta política e de pesquisa. RECIIS- R. Eletr.de Com. Inf. Inov. Saúde 2013; 6(Supl. 4).

4. Araújo IS. Mercado Simbólico: um modelo de comunicação para políticas públicas. Interface (Botucatu) 2004; 8(14):165-178

5. Azevedo APM. Jornalismo de saúde: novos rumos, novas literacias. Comunicação e Sociedade 2012; número especial:185-197.

6. Ruão T, Lopes F, Marinho S. Comunicação e saúde, dois campos em interseção. Comunicação e sociedade 2012; número especial:5-7.

7. Ramos V. Serviço Nacional de Saúde: patrimônio de todos. Primeiro Congresso após 34 anos de vida. Revista Portuguesa de Saúde Pública 2013; 31(2):127-128.

8. Cavaca AG, Vasconcellos-Silva PR. O Mercado da atenção e as doenças midiaticamente negligenciadas. Rev. bras. pesqui. Saúde 2013; 15(4):4-5.

9. Morel CM. Inovação em saúde e doenças negligenciadas. Cad Saude Publica 2006; 22(8):1522-1523.

10. Castro I, Borlido-Santos J, Nunes J, Costa DN. Novos envolvimentos da Ciência com a Sociedade: as oficinas de Ciência na intersecção das Ciências da Vida, as Ciências Sociais e os seus públicos. Coimbra, Porto: Centro de Estudos Sociais/Instituto de Biologia Molecular e Celular, Instituto Nacional de Engenharia Biomédica; 2014. (Relatório de pesquisa).

11. Lopes F, Marinho S, Fernandes L, Araújo R, Gomes S. A saúde em notícia na imprensa portuguesa entre setembro de 2010 e junho 2013. In: Lopes F, Ruão T, Marinho S, Coelho ZP, Fernandes L, Araújo R, Gomes S, organizadores. A saúde em notícia: repensando práticas de comunicação. Braga: CESC; 2013. p. 56-79.

12. Silva PA. A saúde nos media: representações do sistema de saúde e das políticas públicas na imprensa escrita portuguesa. Lisboa: Editora Mundos Sociais; 2011.

13. Portugal. Plano Nacional de Saúde 2012-2016: perfil de saúde em Portugal. Lisboa; 2013.

14. Observatório Português dos Sistemas de Saúde-OPSS. Relatório de Primavera 2013: duas faces da saúde. Coimbra: Mar da palavra; 2013

15. Tobar F, Yalour MR. Como fazer teses em saúde pública: conselhos e ideias para formular projetos e redigir teses e informes de pesquisa. Rio de Janeiro: Editora Fiocruz; 2001.

16. Minayo MCS, Assis SG, ER Souza. Avaliação por triangulação de métodos: abordagem de programas sociais. Rio de Janeiro: Editora Fiocruz; 2005.

17. Associação Portuguesa para Controlo de Tiragem e Circulação-APCT. Análise simples 2013. [acessado 2014 maio 22]. Disponível em: http://www.apct.pt/ Analise_simples.php.

18. Lewins A, Silver C. Using software in qualitative research: a step-by-step guide. London: SAGE publications Ltd; 2007.
19. Bardin L. Análise de Conteúdo. Portugal: Edições 70; 2009

20. Wolf M. Teorias da Comunicação. $5^{\mathrm{a}}$ ed. Lisboa: Editorial Presença; 1999.

21. Romeyer H, Moktefi A. Pour une approche interdisciplinaire de la prévention. Revue Communication et Langages 2013, 176:33-47.

22. Lopes F, Ruão T, Marinho S, Araújo R. A saúde em notícia entre 2008 a 2012: retratos do que a imprensa portuguesa mostrou. Comunicação e sociedade 2012; número especial:129-170.

23. Araújo R, Lopes F. The media coverage of dengue in the Portuguese press: Público, Expresso, Jornal de Notícias and Diário de Notícias. Proceedings of IAMCR 2013 Conference; 2013 jun 25-29; Dublin, Ireland; 2013.

24. Araújo IS, Cardoso JM. Comunicação e Saúde. 20ª ed. Rio de Janeiro: Editora Fiocruz; 2007.

25. Guimarães C. A realidade que não cabe no jornal. Observatório da imprensa; 2014 abr 29. [acessado 2014 maio 22]. Disponível em: http://www.observatoriodaimprensa.com.br/news/view/_ed796_a_realidade_ que_nao_cabe_no_jornal.

26. Medecins Sans Frontieres - MSF. MSF crisis alert: the new face of an old disease: urgent action needed to tackle global drug-resistant TB threat 2014. [acessado 2014 maio 22]. Disponível em: https://www.msf. org.br/arquivos/Doc/Publicacoes/msf $\% 20$ crisis $\% 20$ alert\%20dr-tb\%20final.pdf.

27. Yamey G. The world's most neglected diseases. BMJ 2002; 325(7357):176-177.

28. Nutbeam D. Health promotion glossary. Genebra: World Health Organization; 1998.

29. Hudacek DL, Kuruvilla S, Kim N, et al. Analyzing media coverage of the Global Fund Disease compared with Lower Funded Diseases (Childhood pneumonia, Diarrhea and Measles). PLoS ONE 2011; 6(6):1-9.

30. Ventura FAAN. Perfil das doenças tropicais em Portugal. Acta médica portuguesa 1996; 9(7-9):241-245.

31. Associação Portuguesa de Hemocromatose - APH. A hemocromatose. [acessado 2014 maio 22]. Disponível em: http://www.aphemocromatose.org/Ahemocromatose/tabid/973/Default.aspx.

32. Cançado RD, Chiattone CS. Visão atual da hemocromatose hereditária. Rev Bras Hematol Hemoter 2010; 32(6):469-475.

33. Bourdieu P. O poder simbólico. Rio de Janeiro: Bertrand Brasil; 1989.

34. Romeyer H. La santé à la télévision: l'émergence d'une question sociale. Questions de Communication, n.11, 2007. [acessado 2014 out 31]. Disponível em: http:// questionsdecommunication.revues.org/7328

35. Turke C. Sociedade excitada: filosofia da sensação. Campinas: Editora Unicamp; 2010.

36. Serra GMA, Santos EM. Saúde e Mídia na construção da obesidade e do corpo perfeito. Cien Saude Colet 2003; 8(3):691-701.

37. Marins BR, Araújo IS, Jacob SC. A propaganda de alimentos: orientação, ou apenas estímulo ao consumo? Cien Saude Colet 2011; 16(9):3873-3882. 
38. Cavaca AG, Gentilli V, Zandonade E, Cortellete Júnior M, Emmerich A. A saúde bucal na mídia impressa: análise das matérias jornalísticas nos anos de 2004-2009. Cien Saude Colet 2012; 17(5):1333-1345.

39. Ferreira FR. Cirurgias estéticas, discurso médico e saúde. Cien Saude Colet 2011; 16(5):2373-2382.

40. Romeyer H. Santé et espace public. In: Romeyer H, organizador. Presses de l'EHESP, collection Communication, santé, social. Rennes: Presses de l'EHESP; 2010. p. 5-11.

Artigo apresentado em 01/07/2014

Aprovado em 28/01/2015

Versão final apresentada em 30/01/2015 